\title{
A diagnostic marker for childhood apraxia of speech: the lexical stress ratio
}

\author{
LAWRENCE D. SHRIBERG $\dagger$, THOMAS F. \\ CAMPBELL $\S$, HEATHER B. KARLSSON $\uparrow$, \\ ROGER L. BROWN $\$$, JANE L. MCSWEENY $\dagger$ \\ and CONNIE J. NADLER $†$ \\ $\uparrow$ Waisman Center, University of Wisconsin-Madison, WI, USA \\ $\$$ Research Design and Statistics Unit, School of Nursing, University of \\ Wisconsin-Madison, WI, USA \\ $\S$ Children's Hospital of Pittsburgh, Pittsburgh, PA, USA
}

(Received 12 August 2002; accepted 30 October 2002)

\begin{abstract}
This report includes an extended review of the contemporary inclusionary criteria used to identify children with suspected apraxia of speech (sAOS) and describes findings supporting a lexical stress marker for sAOS. The thesis is that although a deficit in speech praxis is the core disorder in sAOS, only a few diagnostic markers for sAOS assess this speech motor control construct. The proposed marker is a composite lexical stress ratio (LSR) that quantifies the acoustic correlates of stress (frequency, intensity, duration) in bisyllabic word forms. Responses to a lexical stress task were obtained from 35 participants referred for a study of apraxia of speech. Eleven of the children were classified as sAOS, because they met one or both of two investigator groups' provisional criteria for sAOS. The 24 remaining children who did not meet either group's criteria were classified as having speech delay (SD). The first question posed was whether the LSR scores of children with sAOS differed from those of children with SD. Findings were affirmative. Of the six LSRs at the upper and lower extremes of the obtained distributions of LSR scores (approximately $8 \%$ of scores at each end), five $(83 \%)$ were from speakers with sAOS $(p<0.003)$. The second question was whether findings for the sAOS speakers were more consistent with deficits in speech motor control or with deficits in underlying phonological representational aspects of lexical stress. A parsimonious interpretation of the present findings, together with findings from other studies, suggests that they reflect the prosodic consequences of a praxis deficit in speech motor control.
\end{abstract}

Keywords: Assessment, diagnosis, praxis, lexical stress, speech disorders

Address correspondence to: Lawrence D. Shriberg, Phonology Project, Waisman Center, University of Wisconsin-Madison, 1500 Highland Avenue, Madison, WI 53705, USA. e-mail: shriberg@waisman.wisc.edu; website: http://www.waisman.wisc.edu/phonology/index.htm 


\section{Introduction}

The goal of the present and a companion study (Shriberg, Green, Campbell, McSweeny and Scheer, 2003) is to identify diagnostic markers for children whose significant speech disorders are due to a deficit in speech praxis. The following extended overviews provide the empirical background and methodological rationales for the study to be reported. To accommodate nosological needs reviewed elsewhere (Shriberg, Aram and Kwiatkowski, 1997a; Odell and Shriberg, 2001), four terms will be used as follows: (a) apraxia of speech refers to the construct of a speech disorder due to impaired praxis; (b) the capitalized and abbreviated term Apraxia of Speech ( $A O S$ ) refers to the acquired form in adults or children; (c) the capitalized and abbreviated term Childhood Apraxia of Speech $(C A S)$ is reserved for children considered true positives for a developmental form of apraxia of speech; and (d) the capitalized and abbreviated term suspected Apraxia of Speech (sAOS) is used for children whose speech and prosody-voice error patterns, performance on non-speech tasks and/or case histories are consistent with apraxia of speech. No conceptual or clinical distinctions are intended by use of the term apraxia rather than dyspraxia in these four classifications.

\section{Research overview}

\section{Behavioural studies}

A review of English language journals indicates that over 75 case study reports and case-control studies of children with sAOS have been published in the past approximately 50 years. Secondary sources that provide reviews of this literature over the past three decades include Morley (1972), Yoss and Darley (1974), Guyette and Diedrich (1981), Thompson (1988), Stackhouse (1992), Crary (1993), Hall, Jordan and Robin (1993), Velleman and Strand (1994), Ozanne (1995), Shriberg et al. (1997a, c), McCabe, Rosenthal and McLeod (1998) and Caruso and Strand (1999). The goals of descriptive-explanatory studies are to explicate the proximal speech processes underlying apraxia of speech and to speculate on its possible distal etiology, pathophysiology, and implications for treatment. Statistical analyses for descriptive-explanatory goals have typically emphasized tests linking the variable under study with speech processing variables in a number of domains and disciplines (e.g. descriptive linguistic, psycholinguistic, neurolinguistic, speech motor control). There have been few programmatic research findings with sufficient empirical support for theoretical convergence. Rather, the interpretation of descriptive and explanatory findings from the many isolated case studies and case-control reports must be evaluated on their individual conceptual coherence. Evaluative reviews of this body of literature have uniformly concluded that there is little consensus either on the complex of behaviours that defines the disorder or on the explanatory framework that best accounts for its occurrence and natural history.

\section{Genetic studies}

A few behavioural and molecular genetic studies have also used a form of casecontrol design for descriptive-explanatory research in sAOS. Cases have been 
identified by the same sets of inclusionary and exclusionary criteria used in nongenetic designs, but controls are the non-affected relatives of the proband (the index case) and non-affected children and their families matched sociodemographically to proband families. In contrast to the limited number of substantive findings in the sAOS designs referenced above, findings from several programmatic genetic studies offer the promise of an eventual neurobiological account of this disorder.

The major ongoing source of neurobiological information is the study series describing a multigenerational British family, half of whose members have an orofacial apraxia and a speech-language disorder. Molecular genetics findings to date include the identification of a susceptibility gene (FOXP2) that co-segregates with the orofacial apraxia and is inherited as an autosomal dominant trait (Lai, Fisher, Hurst, Levy, Hodgson, Fox, Jeremiah, Povey, Jamison, Green, VarghaKhadem and Monaco, 2000; Lai, Fisher, Hurst, Vargha-Khadem and Monaco, 2001). Neuroimaging and psycholinguistic studies have yielded a number of candidate speech processing loci for the orofacial apraxia, and by inference, for the pattern of speech errors that are presumed to be specific for developmental apraxia of speech (Vargha-Khadem, Watkins, Alcock, Fletcher and Passingham, 1995; Vargha-Khadem, Watkins, Price, Ashburner, Alcock, Connelly, Frackowiak, Friston, Pembrey, Mishkin, Gadian and Passingham, 1998; Watkins, Gadian and Vargha-Khadem, 1999; Alcock, Passingham, Watkins and Vargha-Khadem, 2000b; Watkins, Dronkers and Vargha-Khadem, 2002; Watkins, Vargha-Khadem, Ashburner, Passingham, Connelly, Friston, Frackowiak, Mishkin and Gadian, 2002; Belton, Salmond, Watkins, Vargha-Khadem and Gadian, in press).

It is beyond the scope of the present paper to review the array of findings from studies of the family members who have so generously participated in this research programme begun over a decade ago. Selected findings will be considered later in the present article, and other findings are addressed in a companion paper investigating speech timing in children with sAOS. Essentially, this landmark research programme has led to the possibility of identifying biomarkers for both the orofacial (i.e. nonspeech) apraxia that is genetically transmitted in this family and for the speech disorder in the family that is consistent with sAOS. Links between the genetic, neuroimaging and psycholinguistic findings provide strong support for the hypothesis of a core impairment in praxis underlying both the orofacial apraxia and the apraxia of speech.

Molecular genetic data emerging from Lewis and her colleagues also indicate the presence of a susceptibility gene near the FOXP2 gene in probands ascertained for a speech disorder of unknown origin (Lewis, Freebairn, Taylor, Hansen, Shriberg, Dawson and Iyengar, 2001; Lewis, Freebairn, Hansen and Taylor, 2002; Schick, Kundtz-Kluge, Tiwari, Taylor, Shriberg, Hansen, Freebairn, Lewis and Iyengar, submitted). Of particular interest in the present context is the candidate region identified by the Cleveland group, which co-segregates with a speech disorder (optionally comorbid with language disorder) but not with specific language disorder without speech involvement. Some children with sAOS are included in the group of children linked to the candidate region. Thus, although language disorders are observed in approximately $40 \%-60 \%$ of preschool children with speech disorders (Shriberg and Kwiatkowski, 1994) and in virtually all children with sAOS (Lewis et al., 2002), it is likely that speech delay and sAOS have different genotypes. Such observations are especially important when deliberating the contribution of cognitive-linguistic processes to a disorder defined as an 
impairment of speech praxis, as addressed later in this paper. Molecular genetics studies that include children with sAOS have also been reported for a number of developmental disorders, including autism (e.g. Gernsbacher and Goldsmith, 2002), epilepsy (e.g. Scheffer, 2000) and galactosemia (e.g. Hansen, Henrichsen, Rasmussen, Carling, Andressen and Skjeldal, 1996).

\section{Measurement overview}

\section{Diagnostic checklists for sAOS}

Until a biomarker becomes available to identify children who are true positives for apraxia of speech, proposals of provisional inclusionary criteria continue to appear, commonly termed diagnostic checklists. Such checklists are typically the centrepiece in textbooks, assessment chapters, articles, and especially workshops designed to teach researchers and practitioners how to identify children with sAOS. McNeil's (2002) pointed characterization of such guidelines as tantamount to 'shopping lists' underscores the conceptual limitations with current classification approaches. The central problem is that the array of items on such lists casts too wide a netreminiscent of Guyette and Diedrich's (1981) widely cited critique that childhood apraxia of speech was a clinical entity in search of itself. Lengthy checklists may have sensitivity, but at unacceptable costs to specificity (Campbell, 2002). Such cautions about the use of checklists do not seem overstated given findings such as those by McCabe and colleagues (1998), listing 30 published descriptive features of sAOS that have been proposed from 1982-1993.

Unlike the goals of descriptive-explanatory research in apraxia of speech, the goal of diagnostic-marker research is to identify one or more necessary and sufficient descriptive features of the disorder. Thus, diagnostic-marker studies address the practical need to identify who has the disorder and who does not. For example, in the study to be described, the individual contributions of intensity, frequency and duration changes to inconsistent lexical stress may be informative for descriptive-explanatory goals, but a composite lexical stress ratio was derived for the practical need to classify speakers as positive or negative for sAOS. Diagnosticmarker studies attempt to improve or supplement existing assessment methods. This form of 'bootstrapping' is familiar in the tests and measures literature, where new tests claim improved conceptual, psychometric and/or administrative efficiency attributes. Two constraints are evident in the use of current checklists of inclusionary criteria for sAOS.

\section{The non-linearity constraint with diagnostic checklists}

In addition to the consequences for research and practice of the 'shopping' term in the previous analogy, the analogy to a 'list' underscores a structural problem with current inclusionary criteria for sAOS termed the non-linearity constraint. Lists of purported features of apraxia of speech have the structure of a linear array of autonomous items. However, inspection of the many lists used in research and clinical practice indicates that a non-linear, hierarchical arrangement of these features is warranted, because there are conditional relationships among the proposed markers. Specifically, some listed items describe speech characteristics of sAOS (termed here descriptive features), some describe the structural conditions 
under which descriptors may be especially notable or exacerbated (termed complex contexts), and some items describe the linguistic consequences of descriptors in complex contexts (termed linguistic outcomes). For example, a typical diagnostic checklist for sAOS may include 'significant vowel errors', 'more difficulty with longer utterances' and 'significantly reduced intelligibility'. Notice that each of these items could be placed on one of three tiers indicating their conditional interrelationships: longer utterances (middle tier) is a complex context within which significant vowel errors (highest tier) may lead to significantly reduced intelligibility (lowest tier). The assumption of non-linear, conditional relationships among a list of proposed diagnostic markers forces attention to such conceptual issues and the excessive redundancies found on most lists.

\section{Psychometric constraints with diagnostic checklists}

In addition to the lack of orthogonality in items found on diagnostic checklists for sAOS, the checklists typically also have psychometric constraints. The standard inclusionary guideline is that a child has to be attested as positive on a minimal number or percentage of items on the checklist (e.g. over 50\%) to be classified as having sAOS. Some checklists also compute some type of severity score for children, based on the number of items endorsed. Because any combination of attested linear items will meet the quantitative criterion, checklist 'scores' do not have the properties of a continuous or even an ordinal metric. Notice, too, that as composite measures, the reliability of each classification decision is the product of the individual reliabilities of each combination of listed items used to classify at least one child as sAOS.

In contrast to the association statistics used in descriptive-explanatory studies of sAOS, the statistics used in diagnostic-marker studies are conventional epidemiological tests of diagnostic accuracy. These metrics, such as positive and negative predictive values, sensitivity and specificity, and likelihood ratios, address perindividual classification accuracy, rather than between-group variance in the variables of interest. As suggested in the introduction to this four-paper series, these are the metrics used for differential diagnosis in evidence-based medicine. If put to such tests of diagnostic accuracy, few of the descriptive features, complex contexts, or linguistic outcomes currently included in diagnostic checklists would likely be found to be specific for sAOS. The following two sections describe those descriptive features that do seem to have specificity as the core descriptors of apraxia of speech.

\section{Diagnostic markers in apraxia of speech}

Markers for deficits in speech praxis

As suggested previously, a deficit in praxis is, by definition, the core construct in apraxia. As defined in Ayres (1985), praxis is 'the generation of volitional movement patterns for the performance of a particular action, especially the ability to select, plan, organize, and initiate the motor pattern...'. A challenge in the motor control literature has been to identify from among those four processes, (a) which one or more processes comprise(s) the core of the praxis deficit, (b) how does this core deficit affect downstream processing and (c) how can tasks be constructed to differentiate core deficits from downstream affects?

Of particular significance in the present context are the findings for the British 
family reported by Alcock, Passingham, Watkins and Vargha-Khadem (2002a, b). These two papers report findings for a battery of linguistic and psycholinguistic tasks administered to affected and unaffected family members. Results indicated that the affected speakers and their unaffected controls did not have difficulty in perceptual and productive tasks requiring imitation of melodic patterns. Thus, their ability to imitate stimuli requiring control of intensity and frequency was intact. However, on tapping tasks requiring them to copy rhythms varying only in time (i.e. the taps were of equal loudness), the affected family members had significantly more difficulty than unaffected family members did. These investigators interpreted their preliminary findings as consistent with a 'temporal processing disorder' as the core deficit of the orofacial apraxia.

In the present context, the above findings for rhythm would implicate corollary deficits in processes that generate speech output as the core praxis deficit in apraxia of speech. As suggested above, the experimental challenge is to construct speech tasks that isolate such deficits, particularly when testing young children who are at acquisition points in growth (i.e. maturational control of segmental and suprasegmental forms) and development (i.e. acquisition of linguistic representations and grammatical rules). Responses to real and nonsense word tasks can be affected by constraints in a number of domains, such as cognitive-linguistic (e.g. word-finding), memorial (e.g. working phonological memory), articulatory (i.e. phonetic inventory), or affective domains (e.g. task demands). There are, however, two classes of speech errors whose topographies have been most closely linked to the construct of a praxis deficit.

\section{Segmental markers of $s A O S$}

In the segmental speech domain, there are five descriptive features of a praxis disorder that have face validity as sensitive and specific markers for sAOS. Relative to specificity issues, four other proposed etiological subgroups of speech delay include subtypes that occur as (a) a genetically transmitted quantitative trait (e.g. Schick et al., in submission), (b) a consequence of early recurrent otitis media with effusion (e.g. Shriberg, Flipsen, Thielke, Kwiatkowski, Kertoy, Katcher, Nellis and Block, 2000), (c) a consequence of a maturational delay in speech systems (e.g. Bishop, 2002) or possible dysarthria (Shriberg and McSweeny, 2002), or (d) a correlate of developmental psychosocial involvements (Shriberg, Austin, Lewis, McSweeny and Wilson, 1997b). The five proposed segmental feature descriptors listed in the next paragraph typically do not occur in transcripts of children meeting criteria for one of these four putative etiological subtypes of child speech-sound disorders.

The following five segmental feature descriptors, rank-ordered by the strongest plausible reflection of a praxis problem, are all referenced to information available in a lifespan database of children with speech delay of unknown origin (Austin and Shriberg, 1996): (a) articulatory struggle (groping) particularly on word onsets, (b) transpositional (metathetic) substitution errors reflecting sequencing constraints on adjacent sounds, (c) marked inconsistencies on repeated tokens of the same word type, (d) proportionally increased sound and syllable deletions relative to overall severity of involvement and (e) proportionally increased vowelldiphthong errors relative to overall severity of involvement. As reviewed previously, the present perspective would assign other proposed clinical-descriptive features of sAOS to a 
lower tier as complex contexts (e.g. output restricted to simple syllable and word shapes, more errors on clusters, more errors in multisyllabic words, increased errors on longer units of speech) or to a third tier representing linguistic outcomes of the praxis problem (e.g. delayed onset of speech, slow development of speech, reduced intelligibility, slow progress in treatment).

\section{Suprasegmental markers of sAOS}

In the suprasegmental domain, reference data on prosody-voice characteristics of children with speech delay of unknown origin (Shriberg, Kwiatkowski, Rasmussen, Lof and Miller, 1992) indicate three descriptive features of a praxis disorder that are both sensitive and specific to sAOS: (a) inconsistent realization of stress (i.e. prominence on syllables or words), (b) inconsistent realization of temporal constraints on both speech and pause events and (c) inconsistent oral-nasal gestures underlying the percept of nasopharyngeal resonance. The first two descriptors are described in more detail in the following subsection. The third proposed feature could be included as a segmental marker because the tongue, jaw and velum are articulators. However, it is included as a suprasegmental marker because the nasopharyngeal resonance differences that have been observed in children with sAOS do not have phonemic consequences in English (Shriberg et al., 1997c). Other proposed suprasegmental markers on diagnostic checklists are nonspecific for sAOS (e.g. slow rate and hypernasal resonance are prominent features of certain types of suspected dysarthria; cf. Love and Webb, 2001; Shriberg and McSweeny, 2002) or are more appropriately classified as a complex context or as the linguistic outcomes of the praxis deficit.

\section{Summary}

The thesis developed to this point is that the current inclusionary criteria for sAOS, as reflected in the numerous diagnostic checklists available in the literature, might usefully be restricted to eight descriptive features that are both sensitive to and specific for a deficit in praxis. Other proposed markers from non-speech tasks and case history data may be useful as correlates and mediators of the percept of apraxia of speech, but eventual validation of this disorder requires empirical support for a core deficit in speech praxis. The final section of this overview provides a background for the proposed marker for sAOS studied in the present paper: inconsistent lexical stress.

\section{Inconsistent stress as a diagnostic marker of sAOS}

Changes in the stress (i.e. relative prominence) of syllables, words and phrases within and across utterances are highly planned processes on which speech and language constituents are likely overlaid (Levelt, 1989). Therefore, although typically viewed as a deficit within the suprasegmental domain, inconsistent stress is a linguistically complex variable with correlates in speech and language. The links between inconsistent realization of linguistic stress and the disorder of praxis that defines sAOS are the complex neuromotor commands that control the intensity, frequency and duration of suprasegmental parameters, as well as the movement patterns underlying the five segmental features of apraxia of speech proposed in the previous section. As suggested in the Alcock et al. (2000a, b) papers above and 
addressed in the companion paper in the present issue, a deficit in speech timing may be the core praxis variable that mediates deficits among these domains of speech-language processing.

There are four subtypes of linguistic stress that can be inspected for evidence of a praxis impairment affecting the appropriateness and consistency of intensity, frequency and duration of speech events and the duration of pause events: (a) lexical and contrastive stress (syllable stress within words-governed by semantics, morphology and morphophonemics), (b) sentential stress (syllable and word stress across words - governed by syntax), (c) emphatic stress (syllable, word and phrase stress - governed by pragmatics) and (d) emotional stress (syllable, word and phrase stress-governed by pragmatics and individual affective states and traits). Descriptive-explanatory data and theoretical perspectives on the acquisition of stress, rhythm and timing can be found in early reports by Allen and colleagues (e.g. Tingly and Allen, 1975) and Smith (e.g. Smith 1978), and in more recent programmatic research on the acquisition of prosody in typical and atypical speakers by Goffman and colleagues (Schwartz and Goffman, 1995; Goffman, 1999; Goffman and Malin, 1999; Goffman, Chakraborty and Vink, 2002), Kehoe and colleagues (Kehoe, Stoel-Gammon and Buder, 1995; Kehoe, 1997, 1998), McGregor and colleagues (McGregor, 1997; McGregor and Johnson, 1997) and Snow (1994, 1997, 1998a, b).

\section{Programmatic research on stress as a diagnostic marker of CAS}

The literature on sAOS includes many individual descriptive-explanatory case studies and case-control studies of linguistic stress, as well as several efforts to develop diagnostic markers based on stress task performance. Reviews of these studies are available in the book chapters and review articles on sAOS cited previously. Two study series in the past decade have been specifically concerned with the development of quantitative descriptions of inconsistent stress as a diagnostic marker of childhood apraxia of speech.

\section{The Madison studies}

A series of studies reported by Shriberg and colleagues (Shriberg et al., 1997a, b, c; Velleman and Shriberg 1999; Odell and Shriberg, 2001; Shriberg et al., 2003; Shriberg and McSweeny, 2002) has reported primarily perceptual data on the correlates of lexical and sentential stress in children with sAOS. The primary conclusion from the 1997 series was that a sentential stress deficit described as excessive-equal-misplaced stress was the only segmental or suprasegmental behaviour that differentiated $52 \%$ of 48 children with sAOS from 71 children with speech delay of unknown origin. The types of speech errors and inconsistencies included in diagnostic checklists for sAOS were not observed in these children in conversational speech samples provided by collaborators, and the children also did not make the self corrections of speech and prosodic errors observed in adults with AOS. Therefore, findings were interpreted as support for an inherited deficit that affected these children's linguistic development of stress - specifically, their ability to represent, store and/or access the stress assignments of syllables or words in conversational discourse. Subsequent analyses of the transcripts indicated that the observed stress errors conformed to expectations from metrical phonology 
(Velleman and Shriberg, 1999). These findings were viewed as support for the prior interpretation that the inconsistent realization of sentential stress was more consistent with a delay in linguistic development than with a deficit in speech motor control.

The results of a subsequent study comparing the speech and prosody patterns of 14 adults with acquired AOS to the transcripts of 14 children with sAOS and inappropriate stress yielded three statistically significant dissociations (Odell and Shriberg, 2001). In this comparative study the adults with AOS did not have significant involvement in sentential stress; however, they had significantly slower age-adjusted speech rate and significantly more self-correction errors (termed errors of phrasing). The latter errors assume correct underlying forms, which are presumed in adults who have suffered a neurogenic insult affecting speech production but are not presumed in children with developmental AOS. These findings were interpreted as inconclusive relative to the psycholinguistic locus of the stress deficit. The three dissociations would suggest that the two disorders were not linked by a common problem in praxis, but developmental issues in the failure of speakers with sAOS to self-correct could account for the differences in findings. For example, rather than attribute the lack of phrasing errors (i.e. repetitions and revisions so prominent in the adults) to unstable linguistic representation of stress in children with sAOS, this dissociation could be accounted for by appeal to pragmatic and other developmental variables. That is, children could have realized that their manifest forms were not correct (i.e. which would require correct underlying forms), but either (a) they did not know that an attempt to self-correct is socially appropriate, or (b) they did know that it is appropriate, but they elected not to make the attempt.

Recent findings reported in Shriberg and McSweeny (2002) have motivated a reexamination of the above findings and conclusions. A review of audiocassette-taped speech samples from 100 children with sAOS, including speech samples in which children responded to phonetically challenging words, indicated that the speechsampling environment is closely linked to the frequency of occurrence of the eight types of speech and prosody errors listed previously. Recall that findings for the previous three studies were based solely on conversational speech samples, many of which were from older children who may have had substantially normalized sAOS. The conclusion was that the speech sampling methods in the prior studies likely led to the underestimation of many to most of the five types of segmental errors listed previously as proposed speech markers of sAOS. One conclusion from this study was that assessment protocols might need to include as many as eight different types of sampling conditions to isolate cognitive, linguistic and speech motor processes that may be affected in children with sAOS (cf. Stackhouse and Wells, 1993; Edwards, Fourakis, Beckman and Fox, 1999). As noted in many descriptiveexplanatory studies, there is a large range of severity of involvement in children with sAOS, at both the initial period of pre-treatment identification and throughout a period of typically protracted normalization. The major conclusion reached in the Shriberg and McSweeny technical report, which examined sources for possible false positives and false negatives in the assessment of children with sAOS, was that prior stress findings from the Madison studies were more consistent with a praxis deficit, rather than a deficit in the acquisition of stable underlying representations for stress assignment. 


\section{The Seattle/Duluth studies}

A series of studies by Skinder-Meredith and colleagues (Skinder, Strand and Mignerey, 1999; Skinder, Connaghan, Strand and Betz, 2000; Skinder-Meredith, Stoel-Gammon and Betz, 2000; Skinder-Meredith, Stoel-Gammon, Wright and Betz, 2000; Skinder-Meredith, Stoel-Gammon, Wright and Strand, 2001) has investigated perceptual and acoustic aspects of lexical and sentential stress in children with sAOS. These well controlled studies have included many sampling environments and speech processing constructs, using the set of inclusionary markers proposed by Davis, Jakielski and Marquardt (1998) to identify children with sAOS. Skinder-Meredith and colleagues were the first to quantify tradeoffs between stress and other relevant speech processing variables, including parametric challenges at the level of working phonological memory (real words, nonsense words), stress assignment and phonological/phonetic complexity. These investigators have not observed in their participants with sAOS the excessive-equal and misplaced sentential stress patterns reported in the Madison studies, although they have reported stress differences in both lexical and sentential tasks for these participants. Among other stress-related findings, Skinder-Meredith and colleagues reported that, in comparison to controls, their samples of children with sAOS had: (a) lower percentages of correctly stressed syllables in bisyllabic and multisyllabic words, (b) lower accuracy percentages for lexical stress as phonetic complexity increased for nonsense words but not for real words, (c) lower lexical stress accuracy on iambic words than on trochaic words in nonsense words but not in real words and (d) more intersubject variability in sentential stress.

\section{Statement of the problem}

The goal of the present study was to assess the diagnostic accuracy of an acoustic stress marker for children with sAOS. Lacking a biomarker for apraxia of speech, the design used the independent classification decisions of two investigator groups to identify children with sAOS. Although the primary goal was to develop a valid and reliable marker for CAS using the bootstraps rationale and methods just reviewed, a secondary goal was to speculate on the implication of findings for the psycholinguistic locus of the praxis deficit that defines this proposed clinical entity. The conventional perspective is that the psycholinguistic locus of the deficit is within speech motor control processes, specifically, a deficit in speech praxis. The alternative explanatory perspective is that stress deficits reflect the representational aspects of speech processing, with the representation of stress rules located within cognitive-linguistic levels of processing. Accordingly, excess stress on the normally stressed syllable (or relatively reduced stress on the normally unstressed syllable) would be viewed as consistent with a deficit in speech motor control. Children know the correct stress assignment but have excessive stress on the stressed syllable due to poor motor control. In contrast, relatively reduced stress on the normally stressed syllable in a bisyllabic word (or excess stress on the normally unstressed syllable) would be viewed as support for a representational deficit as the psycholinguistic locus in children with sAOS. The assumption is that such children do not have a stable representation of correct stress assignment. 


\section{Method}

\section{Participants}

\section{Recruitment}

Participants were 35 3-12-year-old children whose speech was assessed in a collaborative speech-genetics study involving investigator groups at the Children's Hospital of Pittsburgh and the Waisman Center in Madison, Wisconsin. Recruitment procedures included presentations and written requests for assistance from over 50 speech-language pathologists at the Pittsburgh hospital and in the greater Pittsburgh area. Clinicians were asked to refer two or more siblings with speech delay, at least one of whom they thought might meet criteria for apraxia of speech. Additional inclusionary criteria, as obtained from case history data and clinical records, were that children have normal hearing sensitivity and language comprehension skills as well as no documented or suspected neurological or development disorder.

Table 1 includes descriptive information for the 35 children whose assessment data were used for the present study. Based on the two investigator groups' criteria for sAOS (described in the following section), the children were classified into two groups: Speech Delay (SD) and suspected Apraxia of Speech (sAOS). The average ages of the children in the two groups were approximately similar at the time their speech was sampled ( $\mathrm{SD}=6$ years, 4 months; $\mathrm{sAOS}=7$ years, 1 month), as were the obtained standard deviations and the ranges of ages for participants in each group. The high proportions of males in each group $(\mathrm{SD}=67 \%, \mathrm{sAOS}=91 \%)$ are consistent with proportions reported in the literatures on speech delay (e.g. Shriberg and Kwiatkowski, 1994) and sAOS (e.g. Hall et al., 1993), respectively. The mean Percentage of Consonants Correct (PCC) scores for all speakers (84\%) was approximately 14 percentage points higher than the average $70 \%$ PCC scores found in clinical samples of younger, preschool-aged children with speech delay (Austin and Shriberg, 1996). Finally, as shown in table 1, the relatively high Intelligibility Index (Shriberg et al., 1997a) scores for both groups were also consistent with the relatively older ages of these children (cf. Lewis et al., 2002). Their average intelligibility, as indexed by the percentage of intelligible words in a sample, was approximately $92 \%$ across groups, with the larger standard deviation for the sAOS group indicating lower levels of intelligibility for many of these speakers.

\section{Protocol}

The 35 children were assessed in a test suite at the Children's Hospital of Pittsburgh. Among other measures, the protocol for the parent study included: (a) a hearing screening set at $20 \mathrm{~dB} \mathrm{HL}$ for the frequencies of 1,2, 4 and $6 \mathrm{KHz}$, (b) the Clinical Evaluation of Language Fundamentals (CELF-P; Wiig, Secord and Semel, 1992; CELF3; Semel, Wiig and Secord, 1995), (c) the Oral and Speech Sequencing subtests from the Verbal Motor Production Assessment for Children (VMPAC; Hayden and Square, 1999), (d) an orofacial screening task (Robbins and Klee, 1987), (e) a 12-minute conversational speech sample and (f) the Lexical Stress Task (LST; to be described). Participants in the parent and current study were required to have a comprehensive standardized score on the CELF3 or CELF-P of 85 or 
Table 1. Description of the participants classified as having speech delay of unknown origin (SD) or suspected apraxia of speech (sAOS)

\begin{tabular}{|c|c|c|c|c|c|c|c|c|c|c|c|c|}
\hline \multirow[b]{2}{*}{ Group } & \multirow[b]{2}{*}{$n$} & \multicolumn{3}{|c|}{ Age (years;months) } & \multicolumn{2}{|c|}{ Sex } & \multicolumn{3}{|c|}{$\begin{array}{c}\text { Percentage of Consonants } \\
\text { Correct }\end{array}$} & \multicolumn{3}{|c|}{ Intelligibility Index } \\
\hline & & $M$ & $S D$ & Range & $\%$ Male & $\%$ Female & $M$ & $S D$ & Range & $M$ & $S D$ & Range \\
\hline Speech Delay (SD) & 24 & $6 ; 4$ & $2 ; 5$ & $3 ; 4-12 ; 0$ & 66.7 & 33.3 & 85.7 & 10.0 & $63.9-99.1$ & 93.1 & 5.9 & $79.3-99.6$ \\
\hline $\begin{array}{l}\text { Suspected Apraxia of } \\
\text { Speech (sAOS) }\end{array}$ & 11 & $7 ; 1$ & $2 ; 1$ & $3 ; 3-10 ; 10$ & 90.9 & 9.1 & 79.3 & 13.0 & $53.4-95.1$ & 89.1 & 11.6 & $59.4-98.3$ \\
\hline Total & 35 & $6 ; 7$ & $2 ; 4$ & $3 ; 3-12 ; 0$ & 74.3 & 25.7 & 83.7 & 11.2 & $53.4-99.1$ & 91.8 & 8.2 & $59.4-99.6$ \\
\hline
\end{tabular}


above and no clinically significant deficit in the structure of the oral mechanism as indicated by results using the Robbins and Klee protocol.

\section{The Lexical Stress Task}

An experimental version of the Lexical Stress Task (LST) required participants to imitate 24 words presented in isolation, including eight words for each of the three bisyllabic stress patterns (trochaic, iambic and spondee). Words were restricted to bisyllabics to reduce expected data loss from probable syllable deletions of more complex forms. Words were also restricted to nouns familiar to young children in order to avoid possible interpretive confounds with deficits in working phonological memory, a constraint associated with less familiar or unfamiliar words (i.e. as assessed in nonsense word repetition tasks). The imitative stimuli for this version of the LST were presented on an audiocassette, with each presentation accompanied by a colourful illustration of the word in a picture book. Each word was presented once. The examiners instructed participants to 'Listen closely, and repeat what you hear'. All stimuli had been recorded in isolation by a woman with Midwestern US speech using a natural speech style. The signal from two tabletop speakers was adjusted to a comfortable listening level for each child.

To minimize the difficulty of the imitative task for the most speech-involved speakers, the words were presented for imitation without a carrier phrase. However, preliminary inspection of the children's responses confirmed the examiners' anecdotal impressions that many children had purposefully (playfully) increased the duration of the second syllables of iambic and spondee words. The lengthened syllables rendered these words inappropriate for stress analysis. Due to the extensive data loss of this type, acoustic analyses were completed only on the eight trochaic words listed below.

\section{Acoustic analyses}

A Kay Elemetrics CSL 4300B system fed by a Tascam 112MKII tape deck was used to digitize participants' responses and to provide spectrographic displays with a 100-point setting and a $300 \mathrm{~Hz}$ bandwidth filter. Preliminary analyses indicated that among a number of candidate acoustic variables on which data had been obtained, six measures of amplitude, frequency and duration were most likely to meet distributional criteria for use in a composite lexical stress ratio. Procedures used to obtain the six acoustic values, termed amplitude maximum, amplitude average, amplitude area, frequency $\left(F_{0}\right)$ maximum, frequency $\left(F_{0}\right)$ area and duration, are described in the following paragraph.

The first phase of the analysis was to segment the vowels in each syllable and to store their durations. Vowels were identified by strong glottal pulsing in the presence of formant structure. Nasalized portions of the vowel were included in the vowel nucleus duration measures, but amplitude peak and frequency peak measures were taken from the non-nasalized portion of the vowel. For each of the vowels in the eight trochaic word forms (chicken, dishes, hammer, ladder, peanut, puppy, robot, window), vowels were segmented from the offset of the preceding consonant to the onset of the following consonant. Pitch contours $(70-350 \mathrm{~Hz}$ analysis range) and amplitude contours (20-80 dB display range, $20 \mathrm{~ms}$ frame length, pitch synchronous) were then produced for each vowel. From the pitch and amplitude contours, respectively, the peak frequency and peak amplitude were visually 
identified. The measurement point was the segment in the vowel at which there was minimal interference from surrounding speech sounds and at which the formant structure of the vowel was relatively stable - typically near the temporal midpoint of the vowel. On the few occasions when a pitch contour could not be produced, the spectrogram was reproduced with 1024 points, and the peak frequency was computed at the point of maximum energy from the $10^{\text {th }}$ harmonic frequency divided by 10. Amplitude averages and frequency averages for each segmented vowel were computed within the CSL application. The amplitude area and frequency area were then derived by multiplying the amplitude average and frequency average by the corresponding vowel duration.

\section{Reliability estimate}

A random sample of 377 (22\%) of the original 1680 measurements (35 participants $\times$ eight trochaic words $\times$ two vowels per word $\times$ three acoustic variables [amplitude average, $\mathrm{F}_{\mathrm{o}}$ average, duration]) was re-measured to estimate intrajudge and interjudge agreement. For the two persons who completed the original measurements, the ranges of the mean intrajudge differences and interjudge differences (divided respectively by a slash) on subsets of these data were as follows: amplitude $=0.4 / 0.9 \mathrm{~dB}$ to $0.8 / 1.3 \mathrm{~dB}, \mathrm{~F}_{0}=1.2 / 14 \mathrm{~Hz}$ to $2.3 / 10.9 \mathrm{~Hz}$ and duration $=$ $4 / 16 \mathrm{~ms}$ to $4 / 18 \mathrm{~ms}$.

\section{Statistical analyses}

Statistical analyses proceeded in four phases. First, ratios were obtained for each of the six acoustic variables per individual for each of the eight trochaic words. The eight ratios per individual were then averaged, providing an average ratio per individual. These ratios reflected the value for the strong (first) syllable divided by the corresponding value for each weak (second) syllable.

Second, a common factor analysis model was used to obtain a single aggregate composite score for the trochaic ratio averages. The factor analysis was conducted using information from each of the six acoustic variables for each of the 35 speakers. All variables loaded positively on a single dimension defined as stress (frequency area $=0.831$, amplitude area $=0.861$, duration $=0.515$, frequency maximum $=0.025$, amplitude average $=0.025$ and amplitude maximum $=0.021)$, but only the first three variables loaded significantly $(p<0.05$, Wald test), accounting for approximately $64 \%$ of the variance. The variables of frequency maximum, amplitude average and amplitude maximum were therefore eliminated.

Third, factor regression scores were obtained on the three significant variables, and the composite score for each speaker was defined as the Lexical Stress Ratio (LSR). The LSR for each individual was defined as $\mathrm{LSR}_{\mathrm{i}}=\mathrm{C}_{1} \mathrm{~S}_{1 \mathrm{i}}+$ $\mathrm{C}_{2} \mathrm{~S}_{2 \mathrm{i}}+\mathrm{C}_{3} \mathrm{~S}_{3 \mathrm{i}}$, where $\mathrm{C}_{1}, \mathrm{C}_{2}$ and $\mathrm{C}_{3}$ were the factor regression scores for the three acoustic measures (frequency area $=0.490$, amplitude area $=0.507$ and duration $=0.303$ ), and $S$ was the averaged ratio score for individual (i) for each acoustic measure.

Because inferential statistics were not appropriate for the present data (due to the directional interest in both low and high LSRs), the fourth step was simply to 
rank-order the distribution of LSR values. As described previously, excessive stress on the normally stressed syllable (yielding a relatively high LSR) would be viewed as more consistent with a deficit in speech motor control. In contrast, reduced stress on the normally stressed syllable (yielding a relatively low LSR) would be viewed as support for a representational deficit as the psycholinguistic locus in children with sAOS.

\section{Results \\ Question 1: do the LSRs of children with sAOS differ from those of children with SD?}

Table 2 includes the distribution of LSR values ordered from highest to lowest for the 35 participants. The ratios ranged from a high of 1.65 to a low of 0.64 (mean $=0.96, \quad$ median $=0.94, \quad$ standard deviation $=0.20, \quad$ skew $=1.18, \quad$ kurtosis $=3.34$ ). Findings from a normality test for the distribution of LSR scores shown in table 2 (Anderson-Darling) did not reject the hypothesis of normality $\left(\mathrm{A}^{2}=0.466, p=0.237\right)$. Thus, the distribution of scores met criteria for parametric analysis, although the kurtosis value of 3.34 indicated that the shape of the LSR distribution was somewhat flat.

Other relevant demographic and speech information about the participants is provided in table 2 , including their status on the six criteria for sAOS used by the two investigator groups. Correlational analyses indicated that LSR was not significantly associated with participants' ages $(r=-0.179, p=0.30)$ or their speech status at the time they were tested for the present study (Percentage of Consonants Correct: $r=0.143, p=0.413$; Intelligibility Index: $r=0.173$, $p=0.320$ ).

Because the LSR distribution was more flat than desirable for use of parametric cut-off criteria, a non-parametric approach was used to determine which LSR values met a conservative criterion for 'atypical' lexical stress. The upper and lower extremes of the distribution were defined as values above the $92^{\text {nd }}$ percentile and values below the $8^{\text {th }}$ percentile, respectively. Such values are approximately equivalent to two standard deviations above and below the mean. Based on these cut-off points, the expected number of the 24 participants with speech delay (SD) that would be in either atypical area of the LSR distribution by chance would be 3.8 (i.e. $2[0.08 \times 24]=3.8$ ). The number of the 11 participants with sAOS that would be expected in either atypical LSR area by chance would be 1.8 (i.e. 2 $[0.08 \times 11]=1.8)$.

As shown in table 2, five of the six most extreme LSR values (three highest, three lowest) were from speakers in the sAOS group. Compared to the number of speakers with sAOS that would have occurred by chance in these areas of the distribution (1.8 speakers or 16\%), the obtained finding of 5 of the $11(46 \%)$ sAOS speakers in these atypical areas was statistically significant $\left(\chi^{2}[\mathrm{df}, 1]=9.052\right.$, $p<0.003)$. Thus, in response to the first question posed of the LSR metric, the LSRs of speakers classified as sAOS were different from those of speakers classified as speech delayed. Specifically, the LSRs of significantly more speakers with sAOS than expected by chance were among both the largest and smallest LSRs obtained for this sample of 35 speakers. 
Table 2. Summary of the Lexical Stress Ratio (LSR) findings for participants in the two speaker groups (SD: Speech Delay; sAOS: Suspected Apraxia of Speech) and inclusionary criteria used by the two investigator groups. The LSR values are ranked from highest to lowest

\begin{tabular}{|c|c|c|c|c|c|c|c|c|c|c|c|c|c|c|}
\hline \multirow{5}{*}{$\begin{array}{l}\text { Partici- } \\
\text { pant No. }\end{array}$} & \multirow{3}{*}{\multicolumn{8}{|c|}{ Participants }} & \multicolumn{6}{|c|}{ Inclusionary Criteria for Participants with sAOS } \\
\hline & & & & & & & & & \multicolumn{3}{|c|}{ Madison Criteria } & \multicolumn{3}{|c|}{ Pittsburgh Criteria } \\
\hline & & & & & & & & & \multirow{3}{*}{$\begin{array}{c}\text { Segmental } \\
\text { Error } \\
\text { Consistency }\end{array}$} & \multicolumn{2}{|c|}{ Suprasegmental } & \multirow{3}{*}{$\begin{array}{c}\text { Segmental } \\
\text { Rate } \\
\text { and } \\
\text { Precision }\end{array}$} & \multicolumn{2}{|c|}{ Suprasegmental } \\
\hline & \multirow{2}{*}{$\begin{array}{c}\text { Lexical } \\
\text { Stress } \\
\text { Ratio }\end{array}$} & \multicolumn{2}{|c|}{ Group } & \multirow{2}{*}{$\begin{array}{c}\text { Age } \\
\text { (yrs;mos) }\end{array}$} & \multicolumn{2}{|c|}{ Sex } & \multicolumn{2}{|c|}{ Speech } & & Sound/ & & & Sound/ & \\
\hline & & SD & sAOS & & M & $\mathrm{F}$ & $\mathrm{PCC}$ & PCCR & & Segregation & Stress & & Transitions & Stress \\
\hline 1 & 1.65 & & $\mathrm{X}$ & $6 ; 0$ & $\mathrm{X}$ & & 81.7 & 88.5 & $\mathrm{X}$ & & & $\mathrm{X}$ & $\mathrm{X}$ & $\mathrm{X}$ \\
\hline 2 & 1.27 & & $\mathrm{X}$ & $5 ; 10$ & $\mathrm{X}$ & & 95.1 & 96.2 & & & & $\mathrm{X}$ & $\mathrm{X}$ & \\
\hline 3 & 1.23 & & $X$ & $3 ; 3$ & $X$ & & 57.6 & 63.8 & $X$ & $X$ & $X$ & $X$ & $X$ & $X$ \\
\hline 4 & 1.14 & $X$ & & $3 ; 5$ & $X$ & & 83.9 & 87.7 & & & & & & \\
\hline 5 & 1.13 & $X$ & & $3 ; 4$ & $X$ & & 78.7 & 82.5 & & & & & & \\
\hline 6 & 1.13 & $X$ & & $8 ; 5$ & & $X$ & 92.0 & 96.7 & & & & & & \\
\hline 7 & 1.09 & $X$ & & $5 ; 11$ & $X$ & & 78.7 & 86.5 & & & & & & \\
\hline 8 & 1.07 & $X$ & & $5 ; 3$ & $X$ & & 95.7 & 96.6 & & & & & & \\
\hline 9 & 1.07 & $X$ & & $3 ; 7$ & $X$ & & 63.9 & 71.9 & & & & & & \\
\hline 10 & 1.05 & $X$ & & $3 ; 4$ & $\mathrm{X}$ & & 71.9 & 88.9 & & & & & & \\
\hline 11 & 1.03 & & $X$ & $9 ; 5$ & $X$ & & 90.8 & 95.7 & & & $X$ & & $X$ & $X$ \\
\hline 12 & 1.01 & & $X$ & $6 ; 5$ & $X$ & & 53.4 & 54.1 & & & & $X$ & $X$ & $X$ \\
\hline 13 & 1.00 & $X$ & & $12 ; 0$ & $X$ & & 90.5 & 97.3 & & & & & & \\
\hline 14 & 0.99 & $X$ & & $9 ; 5$ & & $X$ & 96.6 & 97.7 & & & & & & \\
\hline 15 & 0.96 & $X$ & & $8 ; 10$ & & $X$ & 99.1 & 99.1 & & & & & & \\
\hline 16 & 0.96 & $X$ & & $4 ; 6$ & $X$ & & 77.3 & 83.0 & & & & & & \\
\hline 17 & 0.94 & $X$ & & $7 ; 10$ & $X$ & & 97.9 & 99.2 & & & & & & \\
\hline 18 & 0.94 & $X$ & & $8 ; 3$ & $\mathrm{X}$ & & 87.5 & 94.7 & & & & & & \\
\hline 19 & 0.93 & $X$ & & $5 ; 10$ & $X$ & & 92.2 & 93.9 & & & & & & \\
\hline 20 & 0.93 & $X$ & & $6 ; 3$ & $X$ & & 86.4 & 91.7 & & & & & & \\
\hline 21 & 0.91 & & $X$ & $8 ; 2$ & $X$ & & 75.8 & 82.1 & $X$ & $X$ & $X$ & & & $X$ \\
\hline 22 & 0.91 & $X$ & & $3 ; 6$ & $X$ & & 70.4 & 74.3 & & & & & & \\
\hline 23 & 0.89 & $X$ & & $7 ; 2$ & & $X$ & 87.1 & 92.2 & & & & & & \\
\hline
\end{tabular}


Table 2. (Continued)

\begin{tabular}{|c|c|c|c|c|c|c|c|c|c|c|c|c|c|c|}
\hline \multirow{5}{*}{$\begin{array}{l}\text { Partici- } \\
\text { pant No. }\end{array}$} & \multirow{3}{*}{\multicolumn{8}{|c|}{ Participants }} & \multicolumn{6}{|c|}{ Inclusionary Criteria for Participants with sAOS } \\
\hline & & & & & & & & & \multicolumn{3}{|c|}{ Madison Criteria } & \multicolumn{3}{|c|}{ Pittsburgh Criteria } \\
\hline & & & & & & & & & \multirow{3}{*}{$\begin{array}{c}\text { Segmental } \\
\begin{array}{c}\text { Error } \\
\text { Consistency }\end{array}\end{array}$} & \multicolumn{2}{|c|}{ Suprasegmental } & \multirow{3}{*}{$\begin{array}{c}\text { Segmental } \\
\text { Rate } \\
\text { and } \\
\text { Precision }\end{array}$} & \multicolumn{2}{|c|}{ Suprasegmental } \\
\hline & \multirow{2}{*}{$\begin{array}{l}\text { Lexical } \\
\text { Stress } \\
\text { Ratio }\end{array}$} & \multicolumn{2}{|c|}{ Group } & \multirow{2}{*}{$\begin{array}{c}\text { Age } \\
\text { (yrs;mos) }\end{array}$} & \multicolumn{2}{|c|}{ Sex } & \multicolumn{2}{|c|}{ Speech } & & Sound/ & & & Sound/ & \\
\hline & & SD & sAOS & & M & $\mathrm{F}$ & PCC & PCCR & & Segregation & Stress & & Transitions & Stress \\
\hline 24 & 0.89 & & $\mathrm{X}$ & $8 ; 3$ & $\mathrm{X}$ & & 85.6 & 89.6 & & & & $X$ & $\mathrm{X}$ & $\mathrm{X}$ \\
\hline 25 & 0.88 & $\mathrm{X}$ & & $6 ; 2$ & $\mathrm{X}$ & & 87.2 & 94.0 & & & & & & \\
\hline 26 & 0.84 & $\mathrm{X}$ & & $3 ; 7$ & & $X$ & 85.0 & 89.3 & & & & & & \\
\hline 27 & 0.82 & $X$ & & $9 ; 6$ & & $X$ & 98.0 & 98.2 & & & & & & \\
\hline 28 & 0.80 & & $\mathrm{X}$ & $5 ; 8$ & $\mathrm{X}$ & & 85.2 & 91.2 & $\mathrm{X}$ & & $\mathrm{X}$ & & & \\
\hline 29 & 0.80 & $\mathrm{X}$ & & $8 ; 11$ & & $\mathrm{X}$ & 81.8 & 86.8 & & & & & & \\
\hline 30 & 0.75 & & $\mathrm{X}$ & $7 ; 2$ & $\mathrm{X}$ & & 84.5 & 91.1 & & & & $\mathrm{X}$ & $\mathrm{X}$ & \\
\hline 31 & 0.74 & $\mathrm{X}$ & & $6 ; 2$ & $\mathrm{X}$ & & 70.6 & 78.0 & & & & & & \\
\hline 32 & 0.72 & $X$ & & $4 ; 9$ & $X$ & & 85.2 & 92.6 & & & & & & \\
\hline 33 & 0.71 & & $X$ & $7 ; 0$ & $X$ & & 77.0 & 91.9 & & & $X$ & $X$ & $X$ & $X$ \\
\hline 34 & 0.65 & $\mathrm{X}$ & & $5 ; 7$ & & $\mathrm{X}$ & 98.1 & 99.2 & & & & & & \\
\hline 35 & 0.64 & & $X$ & $10 ; 10$ & & $\mathrm{X}$ & 86.1 & 90.0 & & & $X$ & $\mathrm{X}$ & $\mathrm{X}$ & $X$ \\
\hline
\end{tabular}


Question 2: Are findings for the speakers with sAOS more consistent with possible deficits in speech motor control processes or in representational processes?

Five of the 11 children meeting study criteria for sAOS had LSR values at one or the other range of the distribution defined as atypical. Thus, findings offer potential support for either perspective on the source of perceived stress differences in some children with sAOS. Some simple descriptive analyses were completed to identify possible trends in the table 2 data - information that might aid in the interpretation of findings. In order to use the available information from all 11 participants meeting criteria for sAOS, these participants were divided into three subgroups based on their LSR scores. Participants number 1, 2 and 3 clearly comprised the high group (LSR range $=1.23-1.65$ ); participants $11,12,21$ and 24 were placed in a middle group (LSR range $=0.89-1.03$ ); and participants 28, 30, 33 and 35 were aggregated as the low group (LSR range $=0.64-0.80$ ).

Inspection of the demographic, speech and diagnostic criteria data in table 2 for speakers in the three LSR groups did not suggest the presence of clear trends. Specifically, consistent with the preliminary analyses indicating that age and LSR values were essentially uncorrelated, there were relatively younger and older children in each of the three LSR subgroups. There was also at least one speaker in each of the three subgroups who had relatively low or high scores on each of the two indices of speech involvement. Finally, LSR scores (as divided into the three subgroups) were apparently unrelated to the investigators' classification criteria, as shown by the entries for the 11 children in the six right-most columns in table 2 . Notice especially that the criterion of perceptually coded inappropriate stress was checked for speakers in all three LSR groups by each of the two investigator groups. Most of the other five inclusionary variables were also checked for participants whose LSR values fell into the high, middle and low ranges of the obtained distribution of LSR scores.

\section{Discussion}

The primary diagnostic-marker finding of this study is that a lexical stress task and a composite lexical stress ratio derived from three acoustic features are sensitive to stress differences in children with sAOS. Of the five children with sAOS (comprising $83 \%$ of the scores in the region of the LSR distribution defined as atypical), four $(80 \%)$ were considered to have a deficit in stress as classified perceptually by one or both of the investigator groups. Comment on the implication of findings for assessment and theory begins with the consideration of some validity and reliability issues.

\section{Validity and reliability issues}

\section{Consensual validity}

At the outset of this study, there was no attempt to develop a common set of descriptive features for sAOS to be used by the two investigator groups. Rather, it was decided that findings would have greater concurrent validity if based on the independent classifications of two investigator groups active in apraxia research. Although the classification decisions were similar for 30 of the $35(86 \%)$ speakers (see table 2), differences on the classification of the target sAOS group are 
consistent with the lack of consensus on which children should be classified as having apraxia of speech. Specifically, as percentaged on the 11 children who were classified as positive for sAOS by either investigator group, classification agreement was only $55 \%$ (i.e. the two groups agreed on six of the 11 sAOS classifications).

A substantial number of the between-group disagreements in sAOS classifications were likely attributed to the different sources of information used by each investigator group. The methodological procedure had each investigator group use whatever tasks were needed from the protocol to make an independent classification decision. The Pittsburgh investigators used information from both the speech and non-speech tasks in the protocol. Thus, their classification decisions were based on segmental and suprasegmental deficits observed in the conversational sample, the articulation test, as well as rate and precision deficits observed in the diadochokinetic tasks and the challenging syllable repetition tasks. Note that eight of the ten $(80 \%)$ children classified as sAOS by the Pittsburgh group were considered positive for a deficit in rate and/or precision (table 2). The classifications of the Madison group, in contrast, were based on segmental and suprasegmental behaviours occurring in only the conversational speech sample or the articulation test. Of the seven sAOS classifications made by this group, six (86\%) included a deficit in sentential or lexical stress.

The low rate of between-group agreements on the sAOS classifications also likely reflected differences in the perceptual criteria used in judging segmental and especially suprasegmental status. Notice in table 2 the seemingly similar suprasegmental variables assessed by the two investigator groups, including a speech-timing variable (Madison: sound/syllable segregations; Pittsburgh: sound/syllable transitions) and a stress variable. Although the domains were similar in title, agreement for the 11 children classified as sAOS by either group was only $18 \%$ (2/11) for the timing domain and $64 \%(7 / 11)$ for the stress domain.

These low rates of agreement are not encouraging from the perspective of consensual validity in the classification of sAOS, but there is a sense in which this information contributes concurrent validity support to the primary findings of this study. Notice in table 2 that there was $80 \%(4 / 5)$ classification agreement between investigator groups for the five participants with sAOS in the upper and lower atypical areas of the LSR distribution. Between-group agreement for the other six participants classified as sAOS, whose LSR scores were in the middle or typical range, was only $33 \%$ (2/6 agreements). Thus, in comparison to the substantial between-group consensus on the classification status of the five children with sAOS at the extremes of the distribution (i.e. possible true positives for CAS), the lack of agreement on the remaining six children could support a view that they were less likely to be true positives for CAS.

\section{Construct validity}

Although the statistical findings support the diagnostic validity of the LSR marker, greater construct validity in the form of increased sensitivity to stress differences can probably be achieved for the Lexical Stress Task in several ways. First, inclusion of iambic forms (as originally intended in the stress task) would likely provide added sensitivity, given that iambic forms are marked relative to trochaic forms and hence typically acquired and mastered later (Kehoe, 1997; McGregor and Johnson, 1997; Goffman et al., 2002). Second, studies of larger numbers of 
children would be useful to develop LSR composites with more stable weightings across the three acoustic variables, including the possibility of a combined composite for trochaic and iambic word forms, if indicated. Third, word level analyses of future composite data are likely to indicate that certain words are contributing significantly to the composite scores, whereas other words contribute less and may actually diminish the sensitivity of the metric (cf., Skinder-Meredith et al., 2000). Finally, a computerized assessment approach could provide for more reliable and more efficient data presentation, acquisition and analysis, including increased motivational elements for participants and increased reliabilities and efficiencies of signal capture and signal processing.

\section{Reliability}

The reliability of classification decisions using diagnostic makers of sAOS such as those used in the present study can be improved. As with other perceptual data in communicative disorders, acoustic-aided instrumental methods and well developed training programs with ample exemplars can increase interjudge and intrajudge agreement on these variables. However, until a behavioural marker or biomarker for apraxia of speech is validated as necessary and sufficient, it is likely that independent estimates of the validity and reliability of classifications of children as having sAOS will remain at the levels observed in the current study.

\section{Summary}

The primary finding of this study was that a composite acoustic measure of lexical stress obtained from imitative productions of eight trochaic words appears to be sensitive to the perceptual impression of a deficit in stress. Although findings were statistically significant, the challenge for both theory and method is to understand why some speakers with sAOS had LSR scores in the range defined as typical and others had LSR scores in the atypically excessive stress area or in the atypically reduced stress area. The answer to the first question involves the validity and methodological issues discussed above. One of many possible explanations for the mismatch between the perceptual and the acoustic data is that at least some of the six participants with apparently typical LSR scores may have had some perceptually evident form of a stress deficit that was not captured by the LSR procedure. Additional research should be able to determine if the problem is one of measurement, and if so, how to increase the sensitivity of the Lexical Stress Task and the Lexical Stress Ratio.

\section{Locus of the stress deficit in $\mathrm{sAOS}$}

The second question posed in this study addressed the possible psycholinguistic locus of a stress deficit that has been described as a prominent descriptive feature in most reports of children with sAOS. As concluded from indirect evidence in Shriberg and McSweeny (2002), the view proposed here is that the present findings are more consistent with a praxis deficit in pre-speech planning or programming stages (cf. Odell and Shriberg, 2001; figure 1) than with a representational deficit in the stress assignment of bisyllabic or multisyllabic words. This position is based on two observations about the findings shown in table 2. 


\section{Distributional considerations}

The LSR values in table 2 form a continuous distribution, with only the highest LSR value (1.65) at an appreciable distance from the next highest ranked value. A continuous distribution of stress ratios, with no appreciable discontinuity demarking typical from atypical composite stress ratios, would seem to be more consistent with functions obtained in the motor control literature than those associated with cognitive-linguistic variables. Specifically, if a deficit in the representation of stress was the source of the two lowest LSR values (i.e. reduced stress on the typically stressed syllable), one might expect to see a substantial discontinuity between these values and the typical values obtained by the speakers with SD. The rationale is that the values for linguistic representations are often modelled as binary features; in the present context, the stress assignment of constituent syllables in words would be represented as +stress or -stress. The aggregate influence on LSR scores from feature-based stress assignment would be predicted to sum to considerably lower LSR values than those observed for the low atypical values shown in table 2 . In contrast, typical or atypical motor behaviours are generally modelled as continuously graded. Accordingly, the relatively continuous scores of the three participants with sAOS who had large stressed-tounstressed syllable ratios (i.e. excessive stress on the stressed syllable) would seem to be more consistent with the concept of a praxis deficit in speech motor control.

\section{Subtype considerations}

A second observation on the findings in table 2 concerns the proportion of participants classified as sAOS who had a deficit in stress as assessed in this study. Based on the perceptual data, nine of the $11(82 \%)$ participants classified as sAOS had a deficit in stress. Based on the acoustic data, only five of the 11 participants (46\%) classified perceptually as sAOS had LSR scores at either of the atypical ends of the distribution as defined in this study. As noted previously, these values are consistent with literature findings indicating that most, but not all, children with sAOS are perceived as having some type of prosodic involvement. In Shriberg et al. (1997c), a suggested way to accommodate such findings was to consider the possibility of subtypes of apraxia of speech. The proposal was that some children with sAOS may have a praxis disorder underlying speech change, and others may have a representational (i.e. linguistic) disorder in which sentential and lexical stress assignment are not well developed or sufficiently stable for veridical retrieval.

We now have a different perspective on the prior proposal of subgroups to accommodate the present and prior findings. First, based on findings reviewed previously, it is more correct to conclude that not all children with sAOS have a stress deficit at the time they are assessed. There is increasing evidence from both case studies and case-control designs that both segmental and suprasegmental deficits in sAOS abate over time at more significant rates than proposed in earlier literature. Significant and welcome explanatory factors may include the greater availability of informative diagnostic and referral information from internet sources as well as improved early identification and treatment of children with suspected apraxia of speech by the clinical speech pathology community.

Second, and more pointedly, it is more parsimonious to envision one praxis disorder with varying severity of expression and varying topologic effects, than to envision two subtypes of apraxia, only one of which involves stress deficits. 
Particularly as apraxia of speech is likely to be genetically transmitted, the concept of variability of expression in topology (as well as variability of expression in severity) is consistent with a monogenetic disorder inherited in Mendelian fashion.

Notice in table 2 that of the nine participants whose stress was considered involved by either or both of the investigator groups, eight participants (89\%) also had one or more segmental variables perceived as involved. The parsimony criterion would seek a common explanatory concept for columns of data that are this highly associated. The other causal possibility (in addition to chance association) is that one variable causes the other (i.e. typically that speech deficits lead to compensatory prosody deficits). This latter compensatory or treatmentmediated view of prosodic deficits in childhood apraxia of speech was discussed in detail in Shriberg et al. (1997c). Several types of counter-evidence were offered to suggest that this causal perspective is not tenable in childhood apraxia of speech, mostly based on data indicating that inappropriate prosody is observed in the earliest speech attempts of children with sAOS and that it persists well after speech errors have normalized (cf. Piggott and Kessler Robb, 1999). Thus, in comparison to a subtypes perspective, these several appeals to parsimony are proposed as support for the alternative concept of childhood apraxia of speech as a unitary disorder of speech praxis with variable severity of expression and variable error topology.

\section{Conclusion}

The primary findings of this study support the potential utility of relatively straightforward acoustic markers to identify children with suspected apraxia of speech. The source of the inconsistent realization of lexical stress by at least some speakers with sAOS is proposed to be consistent with the construct of an inherited praxis disorder in speech motor control. Research needs include additional development and cross-validation of a lexical stress task that can be used to explore genotype-phenotype relationships in molecular genetics studies of childhood apraxia of speech. Several such studies are in progress, including improved methods that use computerized acquisition approaches and will provide reference samples from typical speakers, If such studies continue to support a stress deficit as a core descriptive feature of childhood apraxia of speech, a clinical challenge will be to determine intervention techniques that best address linguistic stress in the context of a child's associated speech, language and social adjustment needs.

\section{Acknowledgements}

Our sincere thanks to the speech-language pathologists at the Children's Hospital of Pittsburgh who helped us identify participants for this study and to the children and their parents who volunteered their time to participate in this project. Thanks also to our laboratory colleagues and collaborators in Pittsburgh, Madison and Cleveland for their assistance and contributions at different stages of the project, including Lisa Freebairn, Sharon Gretz, Sheryl Hall, Barbara Lewis, Tammy Nash, Dayna Pitcairn, Carmen Rasmussen, Heather Rusiewicz, Alison Scheer, Jennine Sprangers, David Wilson and Marie Wirka. Special thanks to Jordan Green and Peter Flipsen Jr. for helpful editorial comments and to Katherina Hauner for significant editorial suggestions and assistance. This research is supported by the 
National Institute on Deafness and Other Communicative Disorders, NIDCD DC00496.

\section{References}

Alcock, K. J., Passingham, R. E., Watkins, K. E. and Vargha-Khadem, F., 2000a, Oral dyspraxia in inherited speech and language impairment and acquired dysphasia. Brain and Language, 75, 17-33.

Alcock, K. J., Passingham, R. E., Watkins, K. E. and Vargha-Khadem, F., 2000b, Pitch and timing abilities in inherited speech and language impairment. Brain and Language, 75, 34-46.

Austin, D. and ShriberG, L. D., 1996, Lifespan reference data for ten measures of articulation competence using the Speech Disorders Classification System (SDCS), Tech. Rep. No. 3 (Phonology Project, Waisman Center, University of WisconsinMadison).

Ayres, A. J., 1985, Developmental Dyspraxia and Adult-onset Apraxia (Torrance, CA: Sensory Integration International).

Belton, E., Salmond, C. H., Watkins, K. E., Vargha-Khadem, F. and Gadian, D. G., 2003, Bilateral brain abnormalities associated with dominantly inherited verbal and orofacial dyspraxia. Human Brain Mapping, 18, 194-200.

Bishop, D. V. M., 2002, Motor immaturity and specific speech and language impairment: evidence for a common genetic basis. American Journal of Medical Genetics, 114, 5663.

CAmpbell, T. F., 2002, Apraxia of speech in children: A primary deficit of intra- and intersyllabic timing and transition. Paper presented at the 2002 Symposium on Childhood Apraxia of Speech, Scottsdale, AZ, March.

Caruso, A. J. and Strand, E. A., 1999, Clinical Management of Motor Speech Disorders in Children (New York: Thieme).

Crary, M. A., 1993, Developmental Motor Speech Disorders (San Diego, CA: Singular Publishing Group).

Davis, B. L., Jakielski, K. J. and Marquardt, T. P., 1998, Developmental apraxia of speech: determiners of differential diagnosis. Clinical Linguistics and Phonetics, 12, $25-46$.

Edwards, J., Fourakis, M., Beckman, M. E. and Fox, R. A., 1999, Characterizing knowledge deficits in phonological disorders. Journal of Speech, Language, and Hearing Research, 42, 169-186.

Gernsbacher, M. A. and GoldSmith, H. H., 2002, Toward a dyspraxic subtype of autism spectrum disorder: a research hypothesis. Unpublished manuscript.

Goffman, L., 1999, Prosodic influences on speech production in children with specific language impairment and speech deficits: kinematic, acoustic, and transcription evidence. Journal of Speech, Language, and Hearing Research, 42, 1499-1517.

Goffman, L., Chakraborty, R. and Vink, L., 2002, Physiologic indices of prosodic structure. Paper presented at the 2002 Joint Conference of the $9^{\text {th }}$ International Congress for the Study of Child Language and the Symposium on Research in Child Language Disorders, Madison, WI, July.

Goffman, L. and Malin, C., 1999, Metrical effects on speech movements in children and adults. Journal of Speech, Language, and Hearing Research, 42, 1003-1015.

Guyette, T. W. and Diedrich, W. M., 1981, A critical review of developmental apraxia of speech. In N. J. Lass (Ed.), Speech and Language: Advances in basic research and practice, Volume 5 (New York: Academic Press), pp. 1-49.

Hall, P. K., Jordan, L. S. and Robin, D. A., 1993, Developmental Apraxia of Speech: Theory and clinical practice (Austin, TX: Pro-Ed).

Hansen, T. W., Henrichsen, B., Rasmussen, R. K., Carling, A., Andressen, A. B. and SkJELDAL, O., 1996, Neuropsychological and linguistic follow-up studies of children with galactosaemia from an unscreened population. Acta Pediatrica, 85, 1197-201.

Hayden, D. and Square, P., 1999, Verbal Motor Production Assessment for Children (San Antonio, TX: The Psychological Corporation). 
Kehoe, M., 1997, Stress error patterns in English-speaking children's word productions. Clinical Linguistics and Phonetics, 11, 389-409.

Kenoe, M., 1998, Support for metrical stress theory in stress acquisition. Clinical Linguistics and Phonetics, 12, 1-24.

Kehoe, M., Stoel-Gammon, C. and Buder, E. H., 1995, Acoustic correlates of stress in young children's speech. Journal of Speech and Hearing Research, 38, 338-350.

Lai, C. S. L., Fisher, S. E., Hurst, J. A., Levy, E. R., Hodgson, S., Fox, M., Jeremiah, S., Povey, S., Jamison, D. C., Green, E. D., Vargha-Khadem, F. and Monaco, A. P., 2000, The SPCH1 region on human 7q31: genomic characterization of the critical interval and localization of translocations associated with speech and language disorder. American Journal of Human Genetics, 67, 357-368.

Lai, C. S. L., Fisher, S. E., Hurst, J. A., Vargha-Khadem, F. and Monaco, A. P., 2001, A forkhead-domain gene is mutated in a severe speech and language disorder. Nature, 413, 519-523.

Levelt, W. J. M., 1989, Speaking: From intention to articulation (Cambridge, MA: The MIT Press).

Lewis, B. A., Freebairn, L. A., Hansen, A. C. and Taylor, H. G., 2002, School-age followup of children with apraxia of speech. Paper presented at the 2002 Joint Conference of the $9^{\text {th }}$ International Congress for the Study of Child Language and the Symposium on Research in Child Language Disorders, Madison, WI, July.

Lewis, B. A., Freebairn, L. A., Taylor, H. G., Hansen, A., Shriberg, L. D., Dawson, D. V. and IYENGAR, S., 2001, Family pedigrees of children with suspected developmental apraxia of speech. Paper presented at the Annual Convention of the American Speech-Language-Hearing Association, New Orleans, LA, November.

Love, R. J. and WebB, W. G., 2001, Neurology for the Speech-language Pathologist (Woburn, MA: Butterworth-Heinemann).

McCabe, P., Rosenthal, J. B. and McLeod, S., 1998, Features of developmental dyspraxia in the general speech-impaired population? Clinical Linguistics and Phonetics, 12, $105-126$.

MCGreGor, K. K., 1997, Prosodic influences in children's grammatical morphology. Topics in Language Disorders, 17, 63-75.

McGregor, K. K. and Johnson, A. C., 1997, Trochaic template use in early words and phrases. Journal of Speech, Language, and Hearing Research, 40, 1220-1231.

McNeIL, M. R., 2002, The construct of apraxia of speech. Paper presented at the 2002 Symposium on Childhood Apraxia of Speech, Scottsdale, AZ, March.

Morley, M. E., 1972, The Development and Disorders of Speech in Childhood, third edition (Baltimore, MD: Williams \& Wilkins).

Odell, K. H. and Shriberg, L. D., 2001, Prosody-voice characteristics of children and adults with apraxia of speech. Clinical Linguistics and Phonetics, 15, 275-307.

Ozanne, A., 1995, The search for developmental verbal dyspraxia. In B. Dodd (Ed.), Differential Diagnosis and Treatment of Children with Speech Disorder (San Diego, CA: Singular Publishing Group), pp. 91-109.

Piggott, G. L. and Kessler Robb, M., 1999, Prosodic features of familial language impairment: Constraints on stress assignment. Folia Phoniatrica et Logopaedica, 51, $55-69$.

Robbins, J. and KleE, T., 1987, Clinical assessment of oropharyngeal motor development in young children. Journal of Speech and Hearing Disorders, 52, 271-277.

Semel, E., WiIG, E. H. and SeCORD, W., 1995, Clinical Evaluation of Language Fundamentals (CELF3), third edition (New York: Psychological Corporation, Harcourt Brace).

SCHEFFER, I. E., 2000, Autosomal dominant rolandic epilepsy with speech dyspraxia. Epileptic Disorders, 2 (Suppl. 1), S19-S22.

Schick, J. H., Kundtz-Kluge, A. M., Tiwari, H. K., Taylor, H. G., Shriberg, L. D., Hansen, A., Freebairn, L. A., Lewis, B. A. and Iyengar, S. K., submitted, Linkage and association analysis of families with speech-sound disorder: Evidence for a susceptibility locus on 7q31. Manuscript submitted for publication.

Schwartz, R. G. and Goffman, L., 1995, Metrical patterns of words and production accuracy. Journal of Speech and Hearing Research, 38, 864-888.

Shriberg, L. D., Aram, D. M. and Kwiatkowski, J., 1997a, Developmental apraxia of 
speech: I. Descriptive perspectives. Journal of Speech, Language, and Hearing Research, 40, 273-285.

ShriberG, L. D., Aram, D. M. and Kwiatkowski, J., 1997b, Developmental apraxia of speech: II. Toward a diagnostic marker. Journal of Speech, Language, and Hearing Research, 40, 286-312.

Shriberg, L. D., Aram, D. M. and Kwiatkowski, J., 1997c, Developmental apraxia of speech: III. A subtype marked by inappropriate stress. Journal of Speech, Language, and Hearing Research, 40, 313-337.

Shriberg, L. D., Austin, D., Lewis, B. A., McSweeny, J. L. and Wilson, D. L., 1997a, The Percentage of Consonants Correct (PCC) metric: extensions and reliability data. Journal of Speech, Language, and Hearing Research, 40, 708-722.

Shriberg, L. D., Austin, D., Lewis, B. A., McSweeny, J. L. and Wilson, D. L., 1997b, The Speech Disorders Classification System (SDCS): extensions and lifespan reference data. Journal of Speech, Language, and Hearing Research, 40, 723-740.

Shriberg, L. D., Flipsen, P. JR., Thielke, H., Kwiatkowski, J., Kertoy, M., Katcher, M., Nellis, R. and Block, M., 2000, Risk for speech disorder associated with early recurrent otitis media with effusion: two retrospective studies. Journal of Speech, Language, and Hearing Research, 43, 79-99.

Shriberg, L. D., Green, J. R., Campbell, T. F., McSweeny, J. L. and Scheer, A., 2003, A diagnostic marker for childhood apraxia of speech: the coefficient of variation ratio. Clinical Linguistics and Phonetics, 17, 575-595.

Shriberg, L. D. and Kwiatkowski, J., 1994, Developmental phonological disorders I: a clinical profile. Journal of Speech and Hearing Research, 37, 1100-1126.

Shriberg, L. D., Kwiatkowski, J., Rasmussen, C., Lof, G. L. and Miller, J. F., 1992, The prosody-voice screening profile (PVSP): Psychometric data and reference information for children, Tech. Rep. No.1 (Phonology Project, Waisman Center, University of Wisconsin-Madison).

Shriberg, L. D. and McSweeny, J. L., 2002, Classification and misclassification of childhood apraxia of speech, Tech. Rep. No.11 (Phonology Project, Waisman Center, University of Wisconsin-Madison).

Skinder, A., Connaghan, K., Strand, E. and Betz, S., 2000, Acoustic correlates of perceived lexical stress errors in children with developmental apraxia of speech. Journal of Medical Speech-Language Pathology, 4, 279-284.

Skinder, A., Strand, E. A. and Mignerey, M., 1999, Perceptual and acoustic analysis of lexical and sentential stress in children with developmental apraxia of speech. Journal of Medical Speech-Language Pathology, 7, 133-144.

Skinder-Meredith, A. E., Stoel-Gammon, C. and Betz, S. K., 2000, Quantifying characteristics of developmental apraxia of speech. Paper presented at the Annual Convention of the American Speech-Language-Hearing Association, Washington DC.

Skinder-Meredith, A. E., Stoel-Gammon, C., Wright, R. and Betz, S. K., 2000, The relationship of prosodic and articulatory errors in developmental apraxia of speech. Paper presented at the Annual Convention of the American Speech-LanguageHearing Association, Washington, DC.

Skinder-Meredith, A., Stoel-Gammon, C., Wright, R. and Strand, E., 2001, The effects of articulatory accuracy on prosody in children with developmental apraxia of speech. Paper presented at the Annual Convention of the American Speech-LanguageHearing Association, New Orleans, LA, November.

Smith, B. L., 1978, Temporal aspects of English speech production: a developmental perspective. Journal of Phonetics, 6, 37-67.

SNOw, D., 1994, Phrase-final syllable lengthening and intonation in early child speech. Journal of Speech and Hearing Research, 37, 831-840.

SNOw, D., 1997, Children's acquisition of speech timing in English: a comparative study of voice onset time and final syllable vowel lengthening. Journal of Child Language, 24, $35-56$.

SNow, D., 1998a, Prosodic markers of syntactic boundaries in the speech of 4-year-old children with normal and disordered language development. Journal of Speech, Language and Hearing Research, 41, 1158-1170. 
SNOw, D., 1998b, A prominence account of syllable reduction in early speech development: the child's prosodic phonology of tiger and giraffe. Journal of Speech, Language, and Hearing Research, 41, 1171-1184.

Stackhouse, J., 1992, Developmental verbal dyspraxia I: a review and critique. European Journal of Disorders of Communication, 27, 19-34.

Stackhouse, J. and Wells, B., 1993, Psycholinguistic assessment of developmental speech disorders. European Journal of Disorders of Communication, 28, 331-348.

Tingly, B. M. and Allen, G. D., 1975, Development of speech timing control in children. Child Development, 46, 186-194.

Thompson, C. K., 1988, Articulation disorders in the child with neurogenic pathology. In N. J. Lass, L. V. McReynolds, J. L. Northern and D. E. Yoder (Eds), Handbook of Speech-language Pathology and Audiology (Toronto: BC Decker Inc.), pp. 548-591.

Vargha-Khadem, F., Watkins, K., Alcock, K., Fletcher, P. and Passingham, R., 1995, Praxic and nonverbal cognitive deficits in a large family with a genetically transmitted speech and language disorder. Proceedings of the National Academy of Sciences, 92, 930-933.

Vargha-Khadem, F., Watkins, K. E., Price, C. J., Ashburner, J., Alcock, K. J., Connelly, A., Frackowiak, R. S. J., Friston, K. J., Pembrey, M. E., Mishrin, M., Gadian, D. G. and Passingham, R. E., 1998, Neural basis of an inherited speech and language disorder. Proceedings of the National Academy of Sciences, 95, $12695-12700$.

Velleman, S. L. and Shriberg, L. D., 1999, Metrical analysis of the speech of children with suspected developmental apraxia of speech. Journal of Speech, Language, and Hearing Research, 42, 1444-1460.

Velleman, S. L. and Strand, K., 1994, Developmental verbal dyspraxia. In J. E. Bernthal and N. W. Bankson (Eds), Child Phonology: Characteristics, assessment, and intervention with special populations (New York: Thieme), pp. 110-139.

Watkins, K. E., Dronkers, N. and Vargha-Khadem, F., 2002, Behavioural analysis of an inherited speech and language disorder: comparison with an acquired aphasia. Brain, 125, 452-464.

Watkins, K. E., Gadian, D. G. and Vargha-Khadem, F., 1999, Functional and structural brain abnormalities associated with a genetic disorder of speech and language. American Journal of Human Genetics, 65, 1215-1221.

Watkins, K. E., Vargha-Khadem, F., Ashburner, J., Passingham, R. E., Connelly, A., Friston, K. J., Frackowiak, R. S. J., Mishrin, M. and Gadian, D. G., 2002, MRI analysis of an inherited speech and language disorder: structural brain abnormalities. Brain, 125, 465-478.

Wiig, E. H., Secord, W. and Semel, E., 1992, Clinical Evaluation of Language Fundamentals-Preschool (CELF-P) (New York: Psychological Corporation, Harcourt Brace).

Yoss, K. A. and Darley, F. L., 1974, Developmental apraxia of speech in children with defective articulation. Journal of Speech and Hearing Research, 17, 399-416. 
Copyright $\odot 2003$ EBSCO Publishing 